\title{
Special Issue on the Continuing Subordination of Women in the Development Process (Editorial)
}

\author{
Kate Young*
}

This IDS Bulletin is entirely devoted to a report on IDS Conference 133: The Continuing Subordination of Women in the Development Process, and to some of the papers given at that conference, which was held at the Institute of Development Studies (IDS), 17-22 September 1978.

One of the objectives of the conference was to allow the theoretical concepts developed by the IDS Subordination of Women Workshop (SOW) to be critically evaluated by people working in the same field, as well as to provide a forum at which Third World women's own work could be discussed. Since the subject of women and development covers such a wide range of issues, it was decided early on to limit our discussions to four main topics: the role of women in production and the changes in these roles; the role of women in reproduction (both biological and social) and the changes noted in these roles; the activities of women to further their own development; and the effects of socialist development policies on women's emancipation. Each participant was asked to prepare a paper on an aspect of one of these broad topics. In all some 67 papers were offered and discussed in three plenary and 18 workshop sessions.

Three categories of participants were recruited: those, whether from the First or Third World, whose main concern is empirical research which promotes the elaboration of theoretical concepts adequate for analysing the effects of development policies and programmes on the situation of women in varying forms of society; those who are concerned with policies and/or programmes specially directed to women; and those who are working at grassroots level with women and are therefore often directly concerned with the day-to-day effects of such policies, as well as the effects of socioeconomic change in general (see Pepe Roberts' article). As a direct result of this recruitment strategy, it was decided to limit the size of the conference so as to provide the conditions most likely to enable participants to work together closely. Although our aim was to represent the three categories equally, in the event participation was weighted toward researchers $(32$ researchers to 25 policymakers and grassroots organisers). The academic disciplines represented were overwhelmingly from the social sciences, with economists outnumbered by sociologists and social anthropologists. Again our ideal was to have equal representation from the Third World and the First; in the end however there were 31 participants from Europe and the USA and 26 from the Third World.

The idea behind these choices goes beyond the obvious one that the conference would provide a forum for people working on the same issues; rather we hoped to get policymakers and grassroots organisers to work with academics and researchers (whether of the First or the Third World) on a critical evaluation of the relevance of research and theory building. It is a common complaint that too little is done by researchers to make their work accessible and, equally, that the theoretical questions which spring from work at the grassroots level are rarely addressed by researchers. Although this is a general problem, it is perhaps more acutely felt by women because they are so often forced to work in isolation, with inadequate resources and backup, and outside the more formal structures, and because they have 
much less voice in policymaking than their male counterparts (of relevance here is Ingrid Palmer's article). In part too it is a problem of the audience that each category of worker is forced by the exigencies of her career structure to address; in part, as Moema Viezzer's article asserts, it is a problem of academic imperialism.

The conference was organised in such a way that the first three full working days began with a plenary session in which some of the main theoretical issues were presented by members of the Subordination of Women Workshop. The conference then broke into a number of much smaller workshop sessions. Discussions were lively, if not heated, but unlike the experience of some participants of other conferences there was no confrontation between First and Third World women on the question of getting the main emphasis right. None the less there were problems in terms of language, forms of communication, and levels of abstraction, as well as disagreement as to the relevance and priority of certain of the theoretical concerns to the actual needs of women (particularly those who had been the object of research). The fourth day was devoted to two topics: forms of organisation and practice which encourage self-determination and rupture bonds of dependence, and the effect of socialist policies on women's emancipation.

At the final all-day plenary session participants worked on recommendations which included both general points about the nature of development and research, and more specific suggestions as to areas in which more research needs to be done. In the report on the conference prepared for this issue of the IDS Bulletin all the papers given in the first three days, as well as those on socialism, are briefly described and an indication given of the main issues discussed. The sessions on women's organisations and adequate forms of practice were largely devoted to detailed discussions of the participants' own experiences, and are therefore less easy to summarise. These sessions are therefore only summarily touched on in the conference report, although articles by Moema Viezzer and Laila Parveen Banu have been included in full to fill this gap.

As a concrete demonstration of the fact that the continuing subordination of women is not confined to the Third World but lies at the heart of social and economic organisation of the more highly developed countries, representatives of some groups in the British Women's Movement talked about their work on such questions as domestic violence, and the legal structures maintaining women's dependence in Britain.

For those readers who are unfamiliar with the debates on women and development, a brief summary of the conference framework and the themes which recurred throughout the various discussions of the conference topics will be given as a way of introducing the longer account of the conference papers and discussions. The broad framework of the conference was first, that the theoretical object of our analysis cannot be women but is rather the relations between women and men in society (a point elaborated in greater detail in Ann Whitehead's article; see page 24); and second, that women's position is structured by a double set of determinations arising from relations of gender and relations deriving from the economic organisation of society. This implies looking at the dynamics of capitalist or socialist development and, for Third World countries, the processes of imperialism. It also implies that in most contexts, when talking about women's position, roles or activities, the question of class has to be posed; in others, for example in talking about women's right to birth control, this is not the case.

The main theme of the conference could then be described as the relation between economy and culture: how does culture absorb, transform and mediate the forces unleashed by the drive toward increasing productivity, new forms of production, raising levels of profitability and eradicating differences between types of labour? And conversely, how is culture, or more specifically how are pre-existing forms of relationships between categories of people, and in particular those between women and men, affected by these same forces?

While we may all agree with the general statement that economic change determined by the spread of capitalist relations affects women's position in society, yet neither the content not the direction of these effects can be read off in advance because they do not occur in a vacuum. The relations between women and men are also created and worked out within a number of differing contexts political, social, ideological and economic - and the 
complex interconnections between these various spheres must be analysed so as to see their individual effects on transforming or shaping women's roles or their interdependent effects. Only then it is possible to begin to understand the mechanisms by which economic change acts upon women's position in society, directly or in a mediated way, and to specify the form that the various social relations involving men and women will take.

Traditional gender roles, and the way they have been interlocked in social institutions and are given expression in social values, are crucial factors which have to be taken into account in any analysis of how economic change is translated into new roles for women (and for men), into new forms of relationship between women and men, and into new ideologies (or perhaps merely somewhat transformed old ones). What we are advocating, in short, is a more sophisticated approach to the study of the dialectical relation between economy and culture.

One way of looking at this dialectical relation is through the use of the concept of the sexual division of labour. By this is meant the allocation of tasks throughout society on the basis of sex, cutting across formal economic categories such as that of the productive sector. Discussions on the changing sexual division of labour with the development of capitalist relations centre on the question of what factors come into play either to reallocate existing tasks between the genders (freeing one of them for investment of time in other activities) or to allocate new and additional tasks. In particular, we have to examine why it is that women so consistently get relegated to tasks which are unremunerated even within productive undertakings - for example providing unpaid wage labour for their male kin or husbands. Even when women are incorporated into the remunerated sector, this often takes quite different forms than men's incorporation; furthermore levels of remuneration are universally sex differentiated.

Economic explanations for this in terms of women's lower productivity, their lack of skills, their lack physical strength, etc. are poorly substantiated; in fact a number of studies have demonstrated that women are more productive than men in certain types of work. Other explanations must be sought. These are usually couched in terms of the extra-economic factors which shape not only women's lifetime work profiles, but the universal characterisation of women as only secondarily engaged in production. In this view their primary role is that referred to in the conference as reproduction. By this concept is meant not only biological reproduction but also all those tasks involved in the caring - daily physical and ideological maintenance - not only of children but also of adults, primarily male.

The productive/reproductive distinction is one which has been adopted recently by a number of people working on various problems related to changes in women's position in society. It was also used by the conference as an ordering device in the selection of the main topics. Although the distinction can be useful, it must be kept in mind that it is an artificial one. Without such a recognition there is a danger of conflating activities which are variously described as reproductive, unremunerated, non-productive and domestic. The need to separate out analytically these activities was emphasised by a number of conference participants.

The conference was concerned to establish whether women's reproductive roles are accommodated to their productive ones, and if so, what the crucial intervening variables are which bring these roles in concordance. There was also concern to understand what forces have lead to an ever greater specialisation of women in reproductive tasks as well as to the proliferation of these tasks themselves (such as the increased specialisation of housewifery, the changed attitudes to childhood and the needs of the child, etc.). The need to specify the nature of the link between domestic work, however conceptualised, and the total social system was one of the recurrent themes of the conference.

Part of the argument resolves around the question of whether labour within the capitalist system is reproduced outside the capital-labour relation. This in turn derives both from the arguments about the relation of unwaged domestic labour to waged labour in the advanced capitalist economies, and that of the subsistence or peasant sector to the capitalist sector in the less developed ones. The benefits to the capitalist of cheap labour, of the ability to throw off labour when not needed, of getting out of legal obligations to permanent employees, are observable as in the fact that the capitalist's advantage is women's disadvantage in that it involves women 
becoming trapped within the domestic sphere. But while women clearly do maintain and service the reserve army of cheap labour, the precise nature of the relation of the two forms of women's labour to capital is not clear. To what extent is it conceptually adequate to classify subsistence production as domestic work and thereby equate it with that which metropolitan housewives do? Is production for self-subsistence a remnant of a prior system of productive relations which has been transformed and reduced but none the less stabilised because of the inability of the capitalist system to destroy it? Is it maintained as an effect of the working of the system itself? Or as an effect of the strategies of capitalists as a class because the sector produces, or is a repository for cheap labour?

A second main theme was that of why entry into socialised wage work alone is not a sufficient condition for liberating women. One of the crucial areas here is the question of the wage: what factors do actually determine the level of women's wages? Why are they uniformly low? What leads women to accept such low wages? An allied point is that economic independence does not necessarily follow from women taking up waged work - rather the social relations in which women workers are enmeshed often preclude their control over the allocation of their wages (particularly, but not exclusively, the case with married women). To understand patterns of distribution, we need to relate them to the various forms of the family, relations within the social unit, and in particular within the household. Again, without careful analysis of the context of women workers' lives, no suppositions can be made about the effect of incorporation into social production on women's understanding of their own position, their consciousness of oppression, exploitation or subordination, either as members of a class or as members of a gender.

The nature of relations within the household and the family was the third theme of the conference. It has been said that a history of women's work must be a history of the family, and here we turn again to what is thought to be the nub of the problem of women's subordination. Marriage, and the social relations between women and men which flow from this contract, almost everywhere give men privileged command of women's labour, and the product of their labour, as well as exclusive right to women's sexuality. In societies marked by social inequality whether of class, caste, or superior/inferior lineages, these inequalities are perpetuated from one generation to another in part through the control of women's sexuality. When women are incorporated into wage work, this gender hierarchy is not broken but replicated (male professors, female lecturers; male overseers, female operatives); women get less secure jobs, at lower pay, with less opportunity of advancement than men. Thus their incorporation into waged work is not at all incompatible with the maintenance of forms of the family and of marriage which perpetuate men's domination. What women's incorporation may bring are fears on the part of the male that 'his' women's new economic role may lead to their greater independence in decision-making, for example as to their own sexuality - evidenced by the reluctance of men to allow their women (wives, daughters or sisters) access to contraception. What is important here is to lay bare the ways in which this potential for female self-determination can once again be curtailed (without actually removing women from waged work). It is in this context that the evidence of growing violence against women must perhaps be seen: as well as the more subtle forms of psychological and ideological oppression.

That relations between the genders within the family is a highly explosive political issue has been learned, to their cost, by many progressive legislators. Often, attempts to lessen the unequal balance of power between the genders, through requiring girls to attend school, giving women the vote, etc. (frequently not so as to liberate women but rather to free them for predetermined social ends such as entry into the labour force) is met by firm male opposition. This is often articulated in terms of how any change in traditional family structures lead to social anomie, disturbed or delinquent youth and so on. Here the powerful language of religious beliefs is a weapon which falls more often to the hands of males (and to reactionaries) than females (and to progressives).

It is not only in capitalist societies that the family or more accurately the household is still the site of male power: one of the perplexing features of many socialist societies is support for a form of family which is closely allied to that of the nuclear family within capitalism. In some countries, of course, polygamy is associated with class difference, and the destruction of the latter implies the disappearance of 
the former. But in many countries which claim to be socialist the continuing subordination of women appears due as much to the support for the nuclear family (and in many cases even patrilocality) as to the failure to tackle the issues of women's liberation in a really profound way. Such a failure we believe has to be related to the role of women in the struggle for the new society. Only where women's organisations are strong and not merely an adjunct to the progressive political party, do such questions become a central part of the political debate and struggle around the priorities to be adopted in the planned development of society. 